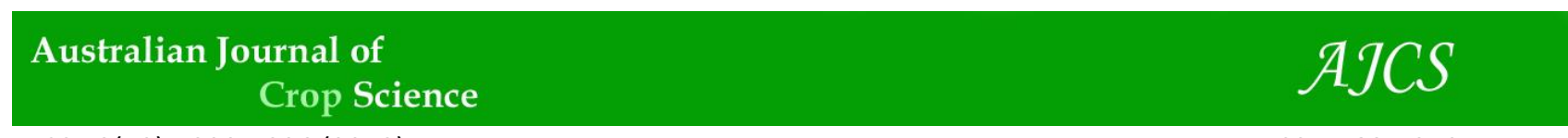

AJCS 13(12):1920-1926 (2019)

ISSN:1835-2707

doi: 10.21475/ajcs.19.13.12.p1289

\title{
Breeding and genetic management of drought in cowpea: Progress and technologies
}

\author{
Maletsema Alina Mofokeng*, Kingstone Mashingaidze
}

Agricultural Research Council, Grain Crops, Private Bag X 1251, Potchefstroom, 2520, Republic of South Africa

\begin{abstract}
Cowpea [Vigna unguiculata (L.) Walp] is one of the most important leguminous crops grown in tropics and sub-tropics worldwide. It serves as a good source of proteins and minerals for nutritional benefits of both humans and animals. However, its production is hindered by recurrent drought conditions associated with climate changes. Under abnormal conditions, drought alone causes grain and fodder yield losses of about $62 \%$ and $56 \%$ of realizable yield, respectively in cowpea. Numerous efforts to mitigate drought through breeding resilient cultivars are underway in many countries. Progress is hampered due to the fact that drought is a complex trait controlled by many genes that is affected by the environment. Consequently, breeding for drought tolerance requires an integration of various knowledge systems and methodologies from multiple plant science disciplines. The success of drought tolerance depends on the accumulation of additive genes, accurate control of stress environments and the use of high throughput selection methods to maximise selection gains. This review aimed at providing perspectives on the status of the progress made thus far on cowpea drought tolerance improvement and the technologies used for genetic management of drought tolerance in cowpea in order to reduce losses incurred due to moisture stress.
\end{abstract}

Keywords: Cowpea, drought tolerance, gene action, molecular marker technologies.

Introduction

Cowpea is one of the most important leguminous crop grown globally belonging to the family Fabaceae. It is believed to have originated in West- and Southern-Africa and is widely distributed in East- and Central-Africa, India, Asia, South- and Central-America. According to FAO (2017), the world production of cowpea is about 5.6 metric tonnes cultivated in an area of 12.6 million hectares. Of the world total cowpea production, Africa produced $95.3 \%$, followed by Asia (2.8\%), America (1.3\%) and Europe (0.6\%). The leading producers in Africa are Nigeria, Niger and Burkina Faso. In South Africa, cowpea is under smallholder farmers systems under dryland conditions in the Limpopo, NorthWest, Mpumalanga and KwaZulu-Natal Provinces (DAFF, 2011).

Cowpea production is widely distributed throughout the tropics and sub-tropical areas of the world. It is mainly grown for human and animal consumption as food and fodder. It is used both as a vegetable and as grain whereby the grain provides an inexpensive source of protein in the diet of many rural households (DAFF, 2011). Cowpea is consumed in different forms. Whole cowpeas are consumed after being stewed, while different products based on a wet milled paste such as akara and moin moin are also produced. Apart from the traditional products, cowpeas are also being processed into flour for the production of bakery products such as cookies and breads (Hallén et al., 2004; McWatters et al., 2005).

Cowpea plays an important role in soil fertility improvement, suppression of weeds and dry grain after maturity. Like most legumes, it has the ability of fixing atmospheric nitrogen, having the advantage of growing well even under poor and low levels of nitrogen and less fertile soils. Cowpea thrives in dry environments, due to its morphological as well as biochemical qualities. The deep-rooted system and less water loss through the stomata and its early maturity are some of the factors that make cowpea adaptable to hostile environments (Gomez, 2004). Although has a competitive niche in sandy soils, it is susceptible to excessively wet conditions, and poorly drained soils (Valenzuela and Smith, 2002).

However, cowpea production is hindered by various factors including abiotic stresses such as drought. Drought is one of the most important factors that affect production worldwide. It causes grain and fodder yield reduction of about $62 \%$ and $56 \%$, respectively (Olubumni, 2015). Climate changes will increase the frequency of drought and flood, particularly in many countries of Africa. It is estimated that by 2050 , water deficits are expected to affect $67 \%$ of the world's population (Ceccarelli et al., 2004). Drought can occur at any stage of crop development. Early season drought stress can affect crop establishment and if it occurs at flowering or pod filling stages, it may results in reduced yields (Tumwesigye and Musitwa, 2002). Drought tolerant varieties are a good means of safeguarding cowpea against the adverse effects of drought. However, drought tolerance is a complex trait that is controlled by many genes (Bernado, 2008). Some of the genes are located as quantitative trait loci (QTL) exhibiting additive and non-additive effects. Drought tolerance has low heritability due to its polygenic nature and the effect of genotype by environment interaction (Khakwali et al., 2012). Despite these challenges, determination of genetic diversity among the cowpea accessions remains the basis of elucidation of the genetic structure and improvement of quantitative traits including drought tolerance. The state of knowledge and 
complementary methodologies towards breeding of drought tolerance in cowpea are often presented disjointedly across various disciplines of plant sciences. Nevertheless, the genomic assisted selection has not yet contributed much in improvement of drought tolerance in cowpea. This review summarizes the literature on the genetic management of drought in cowpea. It highlights yield losses and the implication of drought, mechanism of drought tolerance, selection methods and technologies for drought tolerance.

\section{Effects of drought on growth and development of crops}

Drought is a major production constraint in agriculture worldwide. It is estimated that cultivation on the earth is only possible on $16 \%$ of the potentially arable area due to limited availability of water (Alexandratos and Bruinsma 2012). Drought is occurring on all continents with varying intensity and frequency. Africa is strongly affected by drought almost every 12 years but drought intensified during the years 2009-2011. Drought stress is expected to be more severe in coming years and drought affected areas may double in year 2050 (Li et al., 2009). Recently, South Africa experienced extreme drought conditions since 2015, which caused many crop losses. Drought is a combination of stress effects caused by high temperatures (Prasad et al., 2008) and a lack of water (Campos et al., 2000b). Global climate change is likely to increase the occurrence and severity of drought events, in particular because of the increase of evapo-transpiration induced by rising temperatures (Feng et al. 2013). Lack of adequate soil moisture or water deficit affects the ability of plants to grow and complete a normal life cycle (Moussa and Adbel-Aziz, 2008). Water deficit can have major consequences on growth, development and yield of crops by affecting several physiological, morphological and biochemical processes (Simpson, 1981). Drought causes poor performance and low yields, and sometimes causes a total crop failure.

The impact of drought stress on crop yield depends on the stress timing and intensity and the response of the crop. Drought stress may occur during the early establishment, vegetative phase or reproductive phase. In cowpea cultivation, the most sensitive stages to water deficit or water stress are just prior to and during bloom (Davis et al., 1991), seed filling stage (Cordeiro et al., 1998) and vegetative stage, followed by the flowering and fruiting stages (Carvalho et al., 2000).

\section{Mechanisms of drought tolerance}

Drought tolerance is defined as the ability of plants to live, grow, and yield adequately with limited soil water supply or under periodic water deficiencies (Ashley, 1993). Three mechanisms are used for drought adaptation, drought escape, dehydration avoidance and dehydration tolerance. Drought escape is the ability of the plant to complete its life cycle before the onset of drought stress. This strategy is particularly successful in regions where drought stress occurs at the end of the crop growth cycle. Flowering time is recognized as the most critical trait to select for drought escape. Dehydration avoidance is defined as the plant capacity to sustain high plant water status or cellular hydration under the effect of drought (Blum 2005). Morphophysiological traits like early vigour, deep roots, stomatal regulation and osmotic adjustment contribute to dehydration avoidance. Dehydration tolerance is defined as the relative capacity to sustain or conserve plant function in a dehydrated state (Blum 2005).Traits like accumulation of molecular protectants that allow the plant to maintain, at least partially, its functionality in a dehydrated state participate to dehydration tolerance.

\section{Selection methods and technologies for drought tolerance Phenotyping cowpea for drought tolerance using phenotypic traits}

There are various ways of determining drought tolerance in plants. These include the use of phenotypic traits as selection criteria. Some of the scientists believe that better adapted and high yielding genotypes could be bred more efficiently and effectively if traits that confer yield under drought conditions could be identified and used as selection criteria at the early stages of breeding programmes (Omae et al., 2007; Sharma et al., 2007). However, there are examples where morpho-physiological traits have been used to identify drought tolerant varieties. Matui and Singh (2003) screened for drought tolerance on cowpea genotypes at seedling stage and identified genotype IT96D-604 as tolerant based on the increase in root dry matter per leaf area under mild water-stress conditions, and downward movement of roots (increasing access and use of soil moisture in deep soil layers) under mild and severe water stress conditions. Kumar et al. (2008) used midday drop of leaf relative water content as a screening and selection trait for drought tolerance of cowpea genotypes. The other traits measured for determination and assessment of drought tolerance include: delayed leaf senescence (Gwathmey et al., 1992), stem greenness, recovery of dry weight (Muchero et al., 2008), root architecture (Itani et al., 1992; Silim and Saxena, 1993; Matsui and Singh, 2003), early maturity, reduced leaf area and leaf area adjustment, photosensitivity and indeterminacy (Singh and Matsui, 2002).

\section{Physiological traits correlated with drought tolerance}

The physiological traits used for determination of drought tolerance include chlorophyll content, water use efficiency, water potential, relative turgidity, leaf gas exchange, relative water content, diffusion pressure deficit, chlorophyll stability index and carbon isotope discrimination (Bates and Hall, 1981; Turk and Hall, 1980; Morgan et al., 1991; Hall et al., 1997; Anyia and Herzog 2004a; Souza et al., 2004). Stomatal conductance and abscisic acid synthesis (Cruz De Carvalho et al., 1998), free proline content (Agbicodo et al., 2009) and production of reactive oxygen species (Countour-Ansel et al., 2006) have been used as traits to be monitored in drought tolerance research work. The usefulness of each trait depends on its correlation with grain yield under moisture deficit. The leaf area is related to the plant's metabolism, dry matter production and yield (Severino et al., 2004), being an important production factor and measurement of water use plants when exposed to water deficit (Fernández et al., 1996; Vieira et al., 2000). According to Netto et al. (2005), the indirect determination of chlorophyll content in leaves can be used as a tool to diagnose the integrity of the photosynthetic apparatus when the plants are subjected to environmental adversity. Bastos et al. (2011) used leaf area 
index, chlorophyll content together with yield and yield related traits to determine drought tolerance of cowpea under moisture stress. In most cases, tolerance to water deficit in cowpea was reportedly associated with increased membrane stability, diminished stomata opening, reduced transpiration and smaller leaf area (Labuschagne et al., 2008; Belko et al., 2012).

\section{Molecular marker technologies for drought tolerance}

Drought tolerance in cowpea is governed by multiple genes whose effects are often masked by or interact with the environment. As such, breeding for drought using conventional methodologies is not easy to achieve. Molecular marker technologies are used to identify regions of the genome that harbor the genes that contribute to drought tolerance (Timko and Singh, 2008). If the most important genes can be tagged with molecular markers, they could be reliably introgressed into highly desirable cultivars that are susceptible to drought, thereby, improving their tolerance to drought. The availability of high throughput genotyping platforms provides new opportunities for improvement of complex traits like drought tolerance through marker-assisted breeding (MAB). Batieno (2014) used marker-assisted backcrossing (MABC) to transfer QTLS for yield under drought and stay-green into Moussa local, a farmer preferred cowpea landrace. Muchero et al. (2013) identified seven loci, five of which exhibited evidence suggesting pleiotropic effects (stay-green) between delayed senescence, biomass, and grain yield using SNP markers. Three of the five putative stay-green QTLs, Dro-1, 3, and 7 were identified in both RILs and diverse germplasm with resolutions of $3.2 \mathrm{cM}$ or less for each of the three loci, suggesting that these may be valuable targets for markerassisted breeding in cowpea. Muchero et al. (2010) mapped candidate genes associated with drought tolerance of cowpea, and identified seven restriction fragment length polymorphism (RFLP) markers that may assist in assessment of this trait in cowpea seedlings. There is a need to develop and identify diagnostic molecular markers that are linked to effective drought tolerance QTLs in cowpea for routine applications of MAS in breeding programs. The markers linked to drought tolerance QTLs could be used to predict the presence of specific genes and might help in the transfer of several QTLs into locally adapted cultivars. Presently, low cost and next generation sequencing (NGS) platforms are becoming available. Technologies such as genotype by sequencing (GBS) needs to be considered for screening for drought tolerant QTLs in the resource materials available to breeders. To date, there is lack of information on the gene cloning in cowpea aimed to incorporate drought tolerant QTLs into suitable genetic backgrounds in cowpea.

\section{Mutation breeding and technology}

Mutation technology is used to create variation in the search of desired traits such as drought tolerance. It is an effective technique to increase resilience to drought in crops grown in drought-prone countries. Among the different present approaches, mutagenesis and mutation breeding and the isolation of improved or novel phenotypes in conjunction with conventional breeding programs can result in mutant varieties endowed with new and desirable variations of agrometrical traits. Mutation breeding is the purposeful application of mutations in plant breeding. Tolerant varieties to stresses can be developed by either (1) direct or (2) indirect breeding approaches. Mutagenesis for resistance to abiotic stresses is a well-known efficient breeding approach in order to create new desirable genetic variability, as the use of the traditional breeding methods have narrowed genetic variability in the cultivated crop species over a long period. Mutation was used in cowpea to create genetic diversity and improve drought tolerance and yield productivity. Seeds of the selected line, IT93K129-4 were irradiated with gamma radiation and screened for drought tolerance and yield (Spreeth et al., 2004). Ronde and Spreeth (2007) used mutation technology in obtaining drought tolerant lines giving relatively good yields under drought stress conditions and having favourable traits. The authors found that under drought stress conditions mutant lines 447, 217 and 346 compared best with the parent line, giving yields of $88 \%, 75 \%$ and $75 \%$ of that of the parent line respectively. Mutant line 217 also performed very well in terms of relative water content and free proline concentration. More studies using mutation technology for the development of drought tolerant genotypes with improved yield in various parts of the world where drought is a challenge need to be considered. According to Hallajia (2016), mutation-assisted plant breeding will play a crucial role in the generation of "designer crop varieties" to address the challenges due to drought and the global plant-product insecurity. Molecular mutation breeding will significantly increase both the efficiency and efficacy of mutation techniques in crop breeding. High-throughput DNA technologies for mutation screening such as TILLING (targeting induced limited lesions in genomes), highresolution melt analysis (HRM), ECOTILLING, and so on are the key techniques and resources in molecular mutation breeding. A TILLING approach based on next-generation sequencing has been used in mining of genes associated with drought tolerance in chickpea (Thudi et al. 2014). The $\mathrm{M}_{2}$ population was used for functional validation of droughtresponsive genes.

\section{Genetic diversity and methods used for evaluation of drought tolerance}

Breeding for a target trait largely depend on the existence of genetic diversity within the target and related crop species. The initial population for screening should be large and diverse enough to ensure adequate presence of genetic variability in order to have a strong selection response (Fischer et al., 2003). In addition, more germplasm lines need to be evaluated in order to identify new and betteradapted sources for drought tolerance. Studies conducted elsewhere have indicated that genetic variability for drought tolerance, which, could be utilized in breeding programmes, exists in cowpea (Matsui and Singh, 2003; Chiulele and Agenbag, 2004; Muchero et al., 2008). In these studies, genotypes were evaluated at different crop growth stages (seedling stage, vegetative and reproductive) using different physiological, morphological and phenological traits. This diversity can aid breeders to develop breeding programmes for drought tolerance and help in germplasm conservation strategies. 
Various researchers have used different methods to evaluate genetic variation in drought tolerance (Bidinger et al., 1982). These methods ranged from wooden boxes (MaiKodomi et al., 1999a; Muchero et al., 2008), pots and hydroponic (Ogbonnaya et al., 2003) to simple field screenings (Singh et al., 1999; Chiulele, 2010; Ishiyaku and Aliyu, 2013). However, progress in breeding cultivars for dry environments has been slow, and selection for yield has been mainly achieved by testing advanced lines over several environments and years (Hall et al., 1997; Cattivelli et al., 2008). This is because of the need to assess the yield of large numbers of lines across several environments and years, and the substantial variation from the effects of environment, error and genotype $\mathrm{x}$ environment interactions. Hence, breeding for drought tolerance is a challenging task because of the complexity of drought responses, environmental factors, and their interactions.

\section{Pre-breeding and breeding of drought tolerant cowpea}

One of the most cost-effective strategies in combating the effects of water deficiency in plants is the development of cultivars with improved drought resistance (Rauf, 2008). Considerable progress has been made for breeding plants with traits related to water stress, based on advances in the areas of plant physiology, molecular genetics and molecular biology in other crops (Cattivelli et al., 2008). In cowpea, there is little information available. Sousa et al. (2015) screened and selected cowpea progenies developed through recurrent selection for drought tolerance. Improvement of drought tolerance in cowpea, through the application of a recurrent selection program, depends on traits being inherited in a quantitative manner. Such programs comprise three or more selection cycles conducted in a repetitive manner, such that selection of progenies with enhanced drought tolerance must commence at the first cycle in order to permit future selections. However, in South Africa reports on breeding for tolerance to drought are still limited. Hence, information on drought tolerance is scarce. There is need to evaluate cowpea accessions for adaptability and drought tolerance within the country.

\section{Gene action of drought tolerance in cowpea}

General combining ability is a good measure of additive gene action, whereas specific combining ability is a measure of non-additive gene action (Rojas and Sprague, 1952). Combining ability studies provides useful information on how inbred lines can be combined to produce a productive hybrid or breed novel varieties. Selection and development of parental lines with high combining ability is one of the most important breeding objectives whether the goal is to create a hybrid with strong vigour or develop a pure line cultivar with improved characteristics compared to their parents (Kadam et al., 2013). The genetic variability among the crosses is partitioned into effects due to additive (GCA) or non-additive (SCA) variances (Shiri et al., 2010). Lines with good combining ability are potential lines for use as parents for development of drought tolerant varieties. Information regarding combining ability and nature of gene action governing the inheritance of desirable traits are therefore efficient ways to achieving maximum genetic gain when developing high yielding cowpea cultivars with higher and more stable yields across drought prone regions where it is grown. Mwale et al. (2017) estimated combining ability and heritability in cowpea genotypes under drought stress and non-stress conditions in Uganda. The study revealed that both additive and non-additive genetic effects condition drought tolerance with the predominance of non-additive genetic effects for seed yield, 100 seed weight and number of pods per plant. Olubumni (2015) screened 91 cowpea genotypes for drought tolerance using phenotypic traits and determined the mode of gene action for drought tolerance on $F_{1}$ progenies. The author found that both the additive and non-additive gene effects were important in the control of grain yield and other drought adaptive traits in all research environments. The additive gene action was also identified as more important in the inheritance of yield related traits, 100 -seed weight, number of seeds per pod, Normalized Difference Vegetation Index (NDVI) measured at three different growth stages and the number of pods and seeds per plant under drought stress. High GCA effects were also reported for hundred seed weight, pod per plant and grain yield in cowpea progenies grown under water stress (Carvallo et al., 2012; Alidu et al., 2013). Information on gene action controlling drought tolerance, yield and its associated traits is scarce in cowpea. Romanus et al. (2008) reported that additive gene action was more important than nonadditive gene action in controlling yield, number of seeds per pod, pod length and hundred seed weight. Umaharan et al. (1997) also reported the prevalence of additive gene action over the non-additive gene action for pod length, pod width, pod wall thickness, inter-seed space, hundred seed weight and seediness on vegetable cowpea. However, combining ability and heritability estimates are specific to the germplasm being tested and the environment where the germplasm is tested (Falconer, 1989). Therefore, there is a need to investigate the gene action controlling drought tolerance, yield and yield related traits in germplasm adapted to South Africa. Such information would be useful for cowpea breeding programmes in the country.

\section{Omics}

\section{Genomics}

The development of genomic resources for cowpea has been more recent than those developed for many other crops. Most early efforts in cowpea were focused on molecular diversity and genetic linkage mapping. Genetic diversity studies have used different marker systems as technologies have advanced from the use of allozymes to technques such as next generation sequencing and genotype by sequencing (Sonah et al., 2013). In cowpea, Xiong et al. (2016) used genotype by sequencing to discover single nucleotide polymorphism (SNP) in cowpea and the identified SNP alleles were used to estimate the level of genetic diversity, population structure, and phylogenetic relationships. Highthroughput next generation sequencing (NGS) technologies have opened the way to novel approaches in this area because of their capacity to produce sequence information on an unparalleled scale compared to Sanger sequencing (Pareek et al., 2011). Recently, NGS was used in cowpea to sequence the genome of cowpea aphid-borne mosaic virus isolated from cowpea in Uganda (Mbeyagala et al., 2017). 


\section{Transcriptomics}

Transcriptomes are studied for interpreting functional elements of genome and revealing molecular constituents of cells and tissues (Wang et al. 2009). The cDNA and oligonucleotide microarray technology are the most widely used techniques of transcriptomics studies in legumes. On the other hand, comparative transcriptomics has provided more information about plant's response to diverse stresses. Thus, transcriptomics, together with other biotechnological approaches helps in development of stress tolerance in crops against the climate change. Study of transcriptomes has a significant impact on all the facets of biological sciences as it provides the ability to analyse differences in gene expression of multiple mRNAs both quantitatively and qualitatively (Tan et al. 2009). The key objectives of transcriptomics are to catalogue all the transcripts including mRNAs, noncoding RNAs and small RNAs to determine transcriptional status of genes; to determine 5 'end and 3 'end sites of genome, posttranscriptional modifications and splicing patterns. Transcriptomics also aim to quantify the modulations in gene expression levels during different stress conditions and developmental stages (Wang et al. 2009). In recent years, transcriptomics studies in cowpea for drought tolerance are still limited.

\section{Proteomics}

Proteomics approach is used to investigate the responses of plants to stresses as well as complexity of biochemical processes (Ghosh and Xu, 2014; Gong et al., 2015). Plant stress proteomics has the ability of identifying possible candidate genes that can be used for the genetic enhancement of plants against stresses (Rodziewicz et al., 2014; Barkla et al., 2016). High throughput proteomics has proved to be a powerful tool for the comprehensive identification of drought-responsive proteins in other crops (Mohammadi et al., 2012). However, proteomics research has been reported widely in biotic studies in cowpea but limited in drought tolerance studies. For instance, Villeth et al. (2015) revealed that the results obtained by proteome, transcriptome, and interactome approaches suggest that oxidative stress, ubiquitination, and glucosinolate degradation may be part of cowpea CE 31 resistance mechanisms in response to nematode infection.

\section{Metabolomics}

Studies of drought tolerance in cowpea have focused on proline and ignored possible changes in other compatible metabolites. However, there is increasing evidence that the osmolytes that play major roles in stress tolerance are specific to species and even varieties (Li et al., 2015; Obata et al., 2015). Goufu et al. (2017) looked at individualizing properties of osmotic adjustment vs. osmoprotection in plants, using cowpea as the model species. They reported that the physiological and metabolic changes developed in parallel and drought/recovery responses showed a progressive acclimation of the cowpea plant to stress. Of the 88 metabolites studied, proline, galactinol, and a quercetin derivative responded the most to drought as highlighted by multivariate analyses, and their correlations with yield indicated beneficial effects. These metabolites accumulated differently in roots, but similarly in leaves, suggesting a more conservative strategy to cope with drought in the aerial parts.

\section{Conclusions}

Cowpea is an important leguminous crop grown for human and animal consumption in the tropics and subtropics of the world. Its deep-rooted system and less water loss through the stomata and its earliness in maturity are some of the key factors that make cowpea adaptable to hostile environments. Although cowpea has ability to withstand harsh conditions, recurrent drought that occurs frequently during the growing season alone causes substantial grain and fodder yield losses of about $62 \%$ and $56 \%$, respectively. Breeding for drought tolerance remains the most feasible and economical approach to drought management. Cowpea breeders needs to continuously search for new sources of drought tolerance. Germplasm screening using both phenotypic and genotypic traits is important to identify drought resilient breeding lines. Progress is hampered due to the fact that drought is a complex trait controlled by many genes and is affected by the environment. Consequently, breeding for drought tolerance requires an integration of various knowledge systems and methodologies from multiple plant science disciplines. Success of drought tolerance depends on accumulation of additive genes for drought tolerance, accurate control of stress environments and the use of high throughput selection methods to maximise selection gains. Recent technologies such as High-throughput DNA technologies for mutation breeding, NGS, GBS and genetic engineering should be utilized for drought tolerance improvement in cowpea.

\section{References}

Agbicodo EM, Fakotun CA, Muranaka S, Visser RGF, Linden Vander CG (2009) Breeding drought tolerant cowpea: constraints, accomplishments and future prospects. Euphytica. 167:353-370.

Alidu MS, Atokple IDK, Akromah R (2013) Genetic analysis of vegetative-stage drought tolerance in Cowpea. Greener J Agri Sci. 3(6):481-496.

Anyia AO, Herzog H (2004) Water use efficiency, leaf area and leaf gas exchange of cowpea under mid-season drought. European J Agron. 20:327-339.

Barkla BJ, Vera-Estrella R, Raymond C (2016) Single-cell-type quantitative proteomic and ionomic analysis of epidermal bladder cells from the halophyte model plant Mesembryanthemum crystallinum to identify saltresponsive proteins. BMC Plant Biol. 16(1):110.

Bates LM, Hall AE (1981) Stomatal closure with soil water depletion not associated with changes in bulk leaf water status. Oecol. 50:62-65.

Bastos EA, Nascimento SP, Silva EM, Freire Filho FR, Gomide $\mathrm{RL}$ (2011) Identification of cowpea genotypes for drought tolerance. Rev Cienc Agron. 42:100-107.

Belko N, Zaman-Allah M, Diop NN, Cisse N, Zombre G, Ehlers JD, Vadez V (2012) Restriction of transpiration rate under high vapour pressure deficit and non-limiting water conditions is important for terminal drought tolerance in cowpea. Plant Biol. 15: 304-316. 
Bidinger FR, Mahalaxmi V, Talukdar BJ, Algarswamy G (1982) Improvement of drought resistance in pearl millet. Workshop on principles and methods of crop improvement for drought resistance with emphasis on rice. IRRI, Los Banos, Phillipines. pp. 45-49.

Carvalho LCB, Silva KJD, Rocha M De M, De Sousa M B, Pires, $C$ de J, Nunes JAR (2012) Phenotypic correlations between combining abilities of $F_{2}$ cowpea populations. Crop Breed Appl Biotechnol. 12:211-214.

Cattivelli L, Rizza F, Badeck FW, Mazzucotelli E, Anna M, Mastrangelo Enrico F, Caterina M, Alessandro T, Michele SA (2008) Drought tolerance improvement in crop plants: An integrated view from breeding to genomics. Field Crop Res. 105:1-14.

Ceccarelli S, Grando S, Baum M, Udupa SM (2004) Breeding for drought resistance in a changing climate. In: Rao, S., Ryan, J. (Ed) Challenges and strategies of dryland agriculture. CSSA Special Publication No 32, CSSA and ASA, Madison, WI.pp137-190.

Chiulele RM, Agenbag GA (2004) Plant water relation and proline accumulation on two cowpea (Vigna unguiculata (L.) Walp.) cultivars as a response to water stress. South Afr J Plant Soil. 21:96-100.

Chiulele RM (2010) Breeding cowpea (Vigna unguiculata (L.) Walp.) for improved drought tolerance in Mozambique. Doctor of Philosophy, University of KwaZulu-Natal. 156

Contour-Ansel D, Torres-Franklin ML, Cruz De Carvalho MH, D'Arcy-Lameta A, Zuily-Fodil Y (2006) Glutathione reductase in leaves of cowpea: clonig of two cDNAs, expression and enzymatic activity under progressive drought stress, desiccation and Absicisic Acid treatment Ann Bot. 98:1279-1287.

De Ronde JA, Spreeth MH (2007) Development and evaluation of drought resistant mutant germplasm of Vigna unguiculata. Water SA 33(3):381-386.

Edson AB., Sebastião PN, Everaldo MS, Francisco RFF, Reinaldo LG (2011). Identification of cowpea genotypes for drought tolerance. Rev Ciência Agron. 42(1):100-107.

Falconer DS (1989) Introduction to quantitative genetics. 3rd ed. Longman, New York.

Fernández CJ; Mcinnes KJ, Cothren JT (1996) Water status and leaf area production in water-and nitrogen-stressed cotton. Crop Sci. 36:1224-1233.

Gong F, Hu X, Wang W (2015) Proteomic analysis of crop plants under abiotic stress conditions: where to focus our research? Front Plant Sci. 6:418.

Goufo P, Moutinho-Pereira JM, Jorge TF, Correia CM, Oliveira MR, Rosa EAS, António C, Trindade H (2017) Cowpea (Vigna unguiculata L. Walp.) metabolomics: osmoprotection as a physiological strategy for drought stress resistance and improved yield. Front Plant Sci. 8:586. Doi: $10.3389 /$ fpls.2017.00586.

Ghosh D, Xu J (2014) Abiotic stress responses in plant roots: a proteomics perspective. Front Plant Sci. 5:6.

Gwathmey CO, Hall AE, Madore MA (1992) Adaptive attributes of cowpea genotypes with delayed monocarpic leaf senescence. Crop Sci. 32:765-772.

Hall AE, Thiaw S, Ismail AM, Ehlers ID (1997) Water-use efficiency and drought adaptation of cowpea. In Singh, B.B., Mohan, R.D.L., Dashiell, K.E., Jackai, L.E.N. (Ed.), Advances in cowpea research, IITA-JIRCAS, Ibadan. pp 8798.
Hallajian MT (2016) Mutation Breeding and Drought Stress Tolerance in Plants. In: Hossain M., Wani S., Bhattacharjee S., Burritt D., Tran LS. (Ed.) Drought stress tolerance in plants, Springer, Cham.

Ishiyaku M, Aliyu H (2013) Field evaluation of cowpea genotypes for drought tolerance and Striga resistance in the dry savanna of the north-west Nigeria. Int J Plant Breed Genet. 7:47-56.

Itani J, Utsunomiya N, Shingenaga S (1992) Drought tolerance of cowpea. Studies on water absorption ability of cowpea (Vigna unguiculata (L.) Walp. Var. unguiculata). Japanese J Trop Agri. 36:37-44.

Kumar A, Sharma KD, Kumar D (2008) Traits for screening and selection of cowpea genotypes for drought tolerance at early stages of breeding. J Agri Rural Dev Trop. 109(2):191-199.

Labuschagne MT, Verhoeven R, Nkouanessi N (2008) Drought tolerance assessment of African cowpea accessions based on stomatal behaviour and cell membrane stability. J Agr Sci. 146:689-694.

Li YP, Ye W, Wang M, Yan XD (2009) Climate change and drought: a risk assessment of crop-yield impacts. Clim Res. 39:31-46.

Li X, Lawas LM, Malo R, Glaubitz U, Erban A, Mauleon R, Heuer S, Zuther E, Kopka J, Hincha DK, Jagadish KS (2015) Metabolic and transcriptomic signatures of rice floral organs reveal sugar starvation as a factor in reproductive failure under heat and drought stress. Plant Cell Environ. 38(10):2171-92.

Mai-Kodomi Y, Singh BB, Myers Jr O, Yopp JH, Gibson PJ, Terao $T$ (1999) Two mechanisms of drought tolerance in cowpea. Indian J Genet. 59:309-316.

Matsui T, Singh BB (2003) Roof characteristic in cowpea related to drought tolerance at the seedling stage. Exp Agri. 39:29-38.

Mbeyagala EK, Tukamuhabwa P, Bisikwa J, Holton T, Mukasa SB (2018) Next generation

sequencing reveals the first complete genome sequence of Cowpea aphid borne mosaic virus from Uganda. Genome Announc 6:e01491-17. https://doi.org/10.1128/genomeA.01491-17.

Mohammadi PP, Moieni A, Hiraga S, Komatsu S (2012) Organ-specific proteomic analysis of drought-stressed soybean seedlings. J Proteom. 75:1906-1923.

Muchero W, Roberts PA, Diop NN, Drabo I, Cisse N, Close TJ, Muranaka S, Boukar O, Ehlers JD (2013) Genetic architecture of delayed senescence, biomass, and grain yield under drought stress in cowpea. PLOS ONE 8(7):1-10.

Muchero W, Ehlers JD, Roberts PA (2010) Restriction site polymorphism-based candidate gene mapping for seedling drought tolerance in cowpea [Vigna unguiculata (L.) Walp.]. Theor Appl Genet. 120:509-518.

Netto AT, Campostrini E, De Oliveira JG, Bressan-Smith RE (2005) Photosynthetic pigments, nitrogen, chlorophyll a fluorescence and SPAD-502 readings in coffee leaves. Sci Hortic. 104(02):199-209.

Obata T, Witt S, Lisec J, Palacios-Rojas N, Florez-Sarasa I, Yousfi S, Araus JL, Cairns JE, Fernie AR (2015) Metabolite profiles of maize leaves in drought, heat, and combined stress field trials reveal the relationship between metabolism and grain yield. Plant Physiol. 169(4):2665-83.

Ogbonnaya Cl, Sarr B, Brou C, Diouf O, Diop NN, RoyMacauley H (2003) Selection of cowpea genotypes in 
hydroponics, pots, and field for drought tolerance. Crop Sci. 43:1114-1120.

Olubunmi ID (2015) Genetic analysis of drought tolerance in cowpea [Vigna unguiculata (L.) Walp]. PhD Thesis, University of Ghana. Ghana.

Omae H, Kumar A, Kashiwaba K, Shono M (2007) Assessing drought tolerance of snap bean (Phaseolus vulgaris) from genotypic differences in leaf water relations, shoot growth and photosynthetic parameters. Plant Prod Sci. 10:28-35.

Pareek CS, Smoczynski R, Tretyn A (2011) Sequencing technologies and genome sequencing. J Appl Genet. 52(4):413-435.

Rauf S (2008) Breeding sunflower (Helianthus annuus L.) for drought tolerance. Commun. Biometry Crop Sci. 3:29-44.

Rojas BA, Sprague GF (1952). A comparison of variance components in corn yield trials-111. General and specific combining ability and their interactions with locations and years. Agron J. 44(9):462.

Rodziewicz P, Swarcewicz B, Chmielewska K, Wojakowska A, Stobiecki M (2014) Influence of abiotic stresses on plant proteome and metabolome changes. Acta Physiol Plant. 36: 1-19.

Romanus KG, Hussein S, Mashela WP (2008) Combining ability analysis and association of yield and yield components among selected cowpea lines. Euphytica. 162:205-210.

Severino LS, Cardoso GD, Do Vale LS, Dos Santos JW (2004) Método para determinação da área foliar em mamoneira. Rev Brasil Ol Fibros. 8(1):753-762.

Sharma KD, Kuma A., Singh D, Salisbury P, Kumar A (2007) Assessing drought tolerance in Brassica species by root characteristics and plant water relations. In: Tingdong, F. and Chunyun, G. (Ed.) Proceedings: The 12th International Rapeseed Congress Sustainable Development in Cruciferous Oilseed Crops Production, Wuhan, China, March 26-30, Science Press USA Inc. pp. 448-451.

Silim SN, Saxena SC (1993). Adaptation of Spring-sown chickpea to the Mediterranean basin. II. Factors influencing yield under drought. Field Crop Res. 34:137146.

Singh DP, Chaudhary BD, Kumar A, Sharma KD, Tyagi PK (2004) Agro-physiological basis of resource management and crop improvement in drought prone environment. In: Shanwal, A. V., Panwar, K. S. and Raj, M. (Ed.) Dryland Agriculture Research and Technologies in India: Issues and Strategies, CCS Haryana Agricultural University, Hisar, India. pp. 99-119.

Singh BB, Matsui T (2002) Cowpea varieties for drought tolerance. In: Fakotun C.A., Tarawali, S.A., Singh, B.B., Kormawa, P.M., and Tamo M. (Ed.) Challenges and opportunities for enhancing sustainable cowpea production. International Institute of Tropical Agriculture, Ibadan Nigeria. pp. 297-300.

Singh BB, Mai-Kodomi Y, Terao T (1999) Relative drought tolerance of major rainfed crops of semi-arid tropic. Indian J Genet. 59(4):437-477.

Sonah $\mathrm{H}$, Bastien $\mathrm{M}$, Iquira $\mathrm{E}$, Tardivel A, Légaré $\mathrm{G}$, Boyle $\mathrm{B}$, Normandeau E, Laroche J, Larose S, Jean M, Belzile F (2013) An improved genotyping by sequencing (GBS) approach offering increased versatility and efficiency of SNP discovery and genotyping. PloS One. 8(1):e54603. doi: 10.1371/journal.pone.0054603
Sousa CC, Damasceno-Silva KJ, Bastos EA, Rocha MM (2015) Selection of cowpea progenies with enhanced droughttolerance traits using principal component analysis. Genet Mol Res. 14(4):15981-15987.

Souza RP, Machad EC, Silva JAB, Lagon AMMA, Silveira JAG, 2004. Photosynthetic gas exchange, chlorophyll fluorescence and some associated metabolic changes in cowpea (Vigna unguiculata) during water stress and recovery. Environ Exp Bot. 51:45-56.

Spreeth MH, Slabbert MM, De Ronde JA, Van Den Heever E, Ndou A (2004) Screening of cowpea, bambara groundnut and amaranthus germplasm for drought tolerance and testing of the selected plant material in participation with targeted communities. WRC report no 944/1/04. ISBN no:1-77005-184-8.

Tan KC, Ipcho SVS, Trengove RD, Oliver RP and Solomon PS (2009) Assessing the impact of transcriptomics, proteomics and metabolomics on fungal phytopathology. Mol Plant Pathol. 10:703-715.

Thudi M, Gaur PM, Krishnamurthy L, Mir RR, Kudapa H, Fikre A, Kimurto P, Tripathi S, Soren KR, Mulwa R, Bharadwaj C, Datta S, Chaturvedi SK, Varshney RK (2014) Genomicsassisted breeding for drought tolerance in chickpea. Funct Plant Biol.41:1178-1190.

Turk KJ, Hall AE (1980) Drought adaptation of cowpea. Influence of drought on plant growth and relations with seed yield. Agron J. 72:428-433.

Umaharan P, Ariyanayagam RP, Haque SQ (1997) Genetic analysis of pod quality characteristics in vegetable cowpea (Vigna unguiculata L. Walp.). Sci Hort. 70:281-292.

Vieira RF, Vieira C, Caldas MT (2000) Comportamento do feijão-fradinho na primavera-verão na zona da mata de Minas Gerais. Pesq Agropec Bras. 35(07):1359-1365.

Villeth GR, Carmo LS, Silva LP, Fontes W, Grynberg P, Saraiva M, Brasileiro AC, Carneiro RM, Oliveira JT, Grossi-de-Sá MF, Mehta A (2015) Cowpea-Meloidogyne incognita interaction: Root proteomic analysis during early stages of nematode infection. Proteomics 15(10):1746-1759.

Xiong H, Shi A, Mou B, Qin J, Motes D, Lu W, Ma J, Weng Y, Yang W, Wu D (2016) Genetic diversity and population structure of cowpea (Vigna unguiculata L. Walp). Plos One 11(8): e0160941. doi:10.1371/journal.

Wang Z, Gerstein M, and Snyder M (2009) RNA-Seq: a revolutionary tool for transcriptomics. Nat Rev Genet. 10:57-63. 